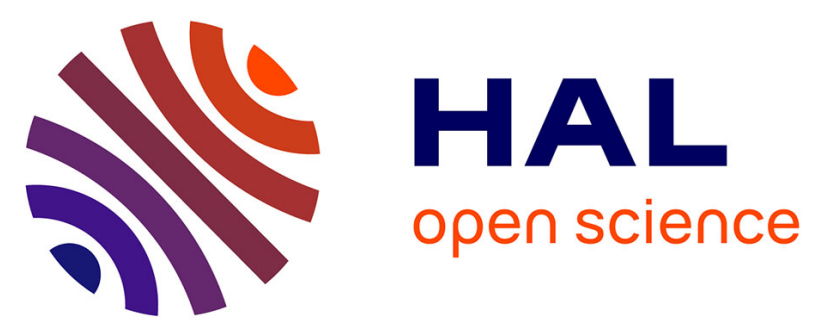

\title{
Naringin at a nutritional dose modulates expression of genes related to lipid metabolism and inflammation in liver of mice fed a high-fat diet
}

Audrey Chanet, Patrycja Wizinska, Sergio Polakof, André Mazur, Catherine Bennetau-Pelissero, Christine Morand, Annie Bérard, Dragan Milenkovic

\section{To cite this version:}

Audrey Chanet, Patrycja Wizinska, Sergio Polakof, André Mazur, Catherine Bennetau-Pelissero, et al.. Naringin at a nutritional dose modulates expression of genes related to lipid metabolism and inflammation in liver of mice fed a high-fat diet. Nutrition and Aging, 2012, 1 (2), pp.113-123. 10.3233/NUA-2012-0010 . hal-01594962

\section{HAL Id: hal-01594962 \\ https://hal.science/hal-01594962}

Submitted on 26 Sep 2017

HAL is a multi-disciplinary open access archive for the deposit and dissemination of scientific research documents, whether they are published or not. The documents may come from teaching and research institutions in France or abroad, or from public or private research centers.
L'archive ouverte pluridisciplinaire HAL, est destinée au dépôt et à la diffusion de documents scientifiques de niveau recherche, publiés ou non, émanant des établissements d'enseignement et de recherche français ou étrangers, des laboratoires publics ou privés. 


\title{
Naringin at a nutritional dose modulates expression of genes related to lipid metabolism and inflammation in liver of mice fed a high-fat diet
}

\author{
Audrey Chanet ${ }^{\mathrm{a}}$, Patrycja Wizinska ${ }^{\mathrm{a}, \mathrm{d}}$, Sergio Polakof ${ }^{\mathrm{a}}$, Andrzej Mazur ${ }^{\mathrm{a}}$, \\ Catherine Bennetau-Pelissero ${ }^{\mathrm{b}}$, Christine Morand ${ }^{\mathrm{a}, *}$, Annie M. Bérard ${ }^{\mathrm{c}, *}$ and Dragan Milenkovic ${ }^{\mathrm{a}}$ \\ a INRA, UMR 1019, UNH, CRNH Auvergne, Clermont-Ferrand; Clermont Université, \\ Université d'Auvergne, Unité de Nutrition Humaine, Clermont-Ferrand, France \\ ${ }^{\mathrm{b}}$ Université de Bordeaux - ENITA Bordeaux 1, Gradignan Cedex, France \\ 'ERU "Facteurs de risque vasculaires", CHU-Université de Bordeaux, Bordeaux, France \\ ${ }^{\mathrm{d}}$ Department of Histology and Embryology, Wroclaw Medical University, Wroclaw, Poland
}

\begin{abstract}
Epidemiological and clinical studies a role for flavanones (predominately found in citrus fruits) in the prevention of cardiovascular disease. Previously, we have shown that a nutritional dose of naringin exerts anti-atherogenic properties together with non HDL-cholesterol lowering effect in a murin model of dietary-induced hypercholesterolemia [1]. The goal of the present study was to explore possible molecular mechanisms of naringin at the hepatic level. To this end, we analyzed the hepatic transcriptome using a microarray approach in response to naringin supplementation $(0.02 \%)$ in mice fed a high-fat highcholesterol diet. Naringin was observed to increase hepatic lipid content (triglyceride and cholesterol) without significant liver dysfunction (ALAT and ASAT activities) or histopathological alterations. Naringin supplementation also significantly improved insulin sensitivity as evaluated by the HOMA index and nutrigenomics revealed that naringin modulated the expression of 1,766 genes. These genes encode proteins involved in different cellular processes, such as lipid metabolism, inflammation and insulin signaling. In conclusion, this study revealed that the hypolipemic and anti-atherogenic effects induced by a nutritionallevel naringin supplementation in high-fat high-cholesterol diet could be related to changes in hepatic lipid metabolism and inflammatory response, revealing new in vivo targets of this flavanone.
\end{abstract}

Keywords: Naringin, liver, high-fat high-cholesterol diet, hypercholesterolemic mouse model, transcriptomic

\footnotetext{
*Corresponding author: Christine Morand, INRA centre de recherche de Clermont-Ferrand/Theix, Unité de Nutrition Humaine (UNH), Equipe Micronutriments, métabolisme et santé (MiMeS), 63122 Saint-Genès-Champanelle, France. Tel.: +33 (0)4 73 6240 84; E-mail: christine.morand@clermont.inra.fr and Annie M. Bérard, CHU-Université Bordeaux, ERU "Facteurs de risque vasculaires", case 49, 146 rue Léo Saignat, 33076 Bordeaux, France. Tel.: +33 (0)5 567956 79; Extension 14616; E-mail: annie.berard@u-bordeaux2.fr.
}

\section{Introduction}

Epidemiological studies have established the protective role of fruit and vegetable consumption against disease development, particularly with regard to cardiovascular diseases (CVD) [2, 3]. It has long been considered that this beneficial effect is attributable to the antioxidant vitamins and carotenoids present in these foods. However, as shown by several 
meta-analysis, large intervention studies with these antioxidants brought disappointing results [4-7] and recently much attention has been paid to polyphenols, bioactive compounds specifically provided by vegetal foodstuffs that may be involved in healthy effects of fruits and vegetables. This is substantiated by epidemiological studies consistently showing a protective effect of some polyphenol-rich foods (fruits, tea, wine, and cocoa or chocolate) against CVD [8-11]. Furthermore numerous studies conducted on animal models with isolated flavonoids $[12,13]$ and on humans with flavonoid-rich foods have shown an improvement in some systemic and functional biomarkers related to CVD risk [14-16].

Among flavonoids, flavanones are found at high concentrations almost exclusively in citrus fruit and citrus-based products [17]. The main flavanones are naringin (NAR) in grapefruit and hesperidin in orange [19]. Some recent findings emerging either from epidemiological and clinical studies have driven interest onto the impact of flavanones on CVD prevention. Indeed, a recent prospective study showed that the dietary intake of flavanones was associated with a lower risk of death due to coronary heart disease and stroke (CHD) [10, 18]. Furthermore, a daily intake of flavanones ranging from 50 to $73 \mathrm{mg}$ [17] has been shown to reduce the rate of CHD mortality by $15 \%$. A possible role for citrus flavanones in cardiovascular protection was strengthened by recent clinical trials showing their beneficial effects on blood pressure and microvascular reactivity $[20,21]$. In animal experiments, naringin (NAR) and naringenin, the aglycone form of NAR, have been shown to exhibit lipid lowering effects, to reduce plasma markers of endothelial dysfunction and to improve insulin sensitivity when added to high-fat high-cholesterol (HF-HC) or cholesterol-rich diets [22-24]. The improvement in hepatic and plasma lipid profiles induced by NAR or naringenin consumption has been related to effects on both cholesterol and fatty acid metabolism. In fact, NAR has been shown to reduce the activity of two hepatic enzymes involved in cholesterol synthesis and storage: 3-hydroxy-3-methyl-glutaryl-CoA reductase (HMG-CoA reductase) and acylcholesterol acyltransferase (ACAT) respectively [25]. In addition, naringenin also up-regulates the expression of genes involved in fatty acid oxidation and downregulated those related to lipogenesis in the liver $[23,26]$. Such effects on hepatic lipid metabolism have been associated with a reduction in atherogenic lipoprotein secretion and in plasma lipid concentrations. These findings highlighted some interesting properties of NAR that could contribute to its anti-atherogenic effects [22-27]. However the physiological relevance of these studies must be interpreted carefully, as most of them have been carried out using supra-nutritional and pharmacological doses of NAR or of naringenin.

Previously we have shown that NAR supplementation at a nutritional dose $(0.02 \%)$ reduced dietary-induced atherosclerosis in wild type mice fed a HF-HC diet [1]. This protective effect was associated with a reduction in plasma non HDL-cholesterol and with an improvement of the atherogenic index (total cholesterol/HDL ratio). Furthermore, as shown by a FPLC lipoprotein profile analysis, NAR particularly affected plasma VLDL cholesterol. The objective of the present work was to further elucidate the mechanisms underlying the effects of NAR on lipid metabolism, focusing at the hepatic level. In the present work we examined effects of NAR in mice fed a diet rich in cholesterol, saturated fat and sucrose, a diet known to induce insulin resistance. We aimed to assess to what extent and by which mechanisms dietary NAR is able to modulate alterations of the hepatic metabolism induced by this atherogenic and diabetogenic diet using transcriptomic approach.

\section{Materials and methods}

\subsection{Mice and diets}

We used a dietary-induced model of atherosclerosis, namely wild-type mice (C57BL/6J) (Charles River laboratories, L'Arbresle, France) on a HF-HC diet [2-29]. Male mice were housed in a temperature-controlled $\left(22 \pm 0.8^{\circ} \mathrm{C}\right)$ pathogen-free environment on a 12 -h light-dark cycle and with free access to food and water. All animal experiments were performed according to the French Ministry of Agriculture section of Health and Animal Protection (approval number 33-04476), the Institutional Ethics Committee of the INRA (decree number 87-848) and approved by Valorization Unit of the University of Bordeaux 2 under the agreement number: R-45GRETA-F1-04. All procedures were carried out in compliance with standards for use of laboratory animals. Mice were fed a standard breeding diet A03 (Safe, Epinay-sur-Orge, France) before the 
beginning of the experiment. After a three week adaptation period, 8-week-old mice were randomly divided into two groups ( $n=15$ per group) and fed ad libitum for 18 weeks a HF-HC diet (15\% fat, $1.25 \%$ cholesterol, $0.5 \%$ cholic acid in Cocoa Butter Diet with $75 \%$ Purina Mouse Chow \#5015, TD.90221, Harlan Teklad, USA) supplemented or not with $0.02 \%$ (w/w) of NAR (Sigma, Saint-Quentin L'Abresles, France). The dose used in the present study corresponds to a human equivalent dose of $100 \mathrm{mg}$ NAR, which according to the UK Food Standard Agency, is the amount of NAR provided by the consumption of 1.5 servings of grapefruit juice or by one fruit. No significant difference in weight between the two groups was observed. At the end of the 8 -week period, mice were fasted for $4 \mathrm{~h}$, and blood was drawn from retro-orbital veins in the morning in tubes containing EDTA. Plasma samples were obtained by centrifugation at $2400 \mathrm{~g}$ for $20 \mathrm{~min}$ at $4^{\circ} \mathrm{C}$, separated and divided into aliquots, then stored frozen $\left(-80^{\circ} \mathrm{C}\right)$ until analyzed. At the end of the 18-week period, non-fasted mice were sacrificed under pentobarbital anesthesia. The organs were washed with physiologic saline solution maintained at $37^{\circ} \mathrm{C}$ by direct injection in the heart's left ventricle.

\subsection{Liver lipids, histological examination and plasma hepatic enzymes}

To establish the hepatic lipid content, livers from non-fasted mice of each study group were harvested, minced and extracted according to Folch [30], then analyzed for total cholesterol (TC) and triglycerides (TG) using commercial enzymatic kits (BioMérieux, Marcy l'Etoile, France). Some liver samples were also fixed in $10 \%$ buffered formalin and embedded in paraffin, sliced and stained with hematoxylin/eosin (Sigma, Saint-Quentin Fallavier, France) to evaluate liver structure. Finally, fasted plasma levels of alanine aminotransferase (ALAT) and aspartate aminotransferase (ASAT) were determined using an automated analyzer (Modular, Roche Diagnostics, Meylan, France).

\subsection{Plasma glucose and insulin}

Glycemia was determined according to the manufacturer (BioMérieux, Marcy l'Etoile, France). Mouse insulin was assayed in duplicate in the same test battery by using a quantitative sandwich enzyme immunoassay technique (R\&D Systems, Lille, France). Intra- and inter-assay coefficients of variation (CV) were $<5 \%$ and $<9 \%$, respectively, with a detection limit of $80 \mathrm{pg} / \mathrm{mL}$ insulin. Homeostatic model assessment for insulin resistance (HOMA) was calculated as a surrogate for insulin resistance, as described elsewhere (Mather, 2009).

\subsection{Microarray analysis}

A fraction of the liver from both batches of mice ( $n=4$ treated mice and $n=4$ untreated mice) was collected and immediately put into RNAlater (Sigma, France). Transcriptomic analysis was performed on livers using pangenomic oligonucleotide Op Arrays ${ }^{\left({ }^{(\mathrm{M}}\right)}$ (Operon, Cologne, Germany).

\subsubsection{RNA extraction and fluorescent cDNA labeling}

Liver samples were homogenized in lysis buffer for total RNA extraction using the SV Total RNA Isolation System (Promega, Madison, WI, USA) as recommended by the manufacturer. Total RNAs were extracted from 8 livers: 4 from mice fed control diet and 4 from mice fed the diet supplemented with NAR and the quality of total RNA was monitored in $1 \%$ agarose gel subjected to electrophoresis. With the ChipShot ${ }^{\mathrm{TM}}$ Direct Labeling System kit (Promega), cDNAs were obtained from $5 \mu \mathrm{g}$ of total RNA with $1 \mu \mathrm{L}$ of random primers, $1 \mu \mathrm{L}$ of oligo(dT), and labeling was performed with $\mathrm{Cy}^{\mathrm{TM}} 3$ - or $\mathrm{Cy}^{\mathrm{TM}}$ 5-dCTP (Amersham Biosciences, Orsay, France). The labeled cDNAs were purified by application to an equilibrated filter cartridge using the ChipShot ${ }^{\mathrm{TM}}$ Membrane Clean-Up System (Promega). Quantities and labeling efficiencies of labeled cDNAs were determined by measuring the absorbance at 260, 550 and $650 \mathrm{~nm}$ using a ND-1000 spectrophotometer (Thermo Scientific, Wilmington, DE, USA).

\subsubsection{Hybridization}

Hybridization was carried out on the Operon mouse microarray (Operon). Array-Ready OligoSet Mouse Genome version 4.0 contains 35,852 longmer probes representing approximately 24,000 genes. Eight microarrays were used for a total of 4 independent comparisons. Hybridization was carried out in a Ventana hybridization system (Ventana Medical Systems, S.A, Illkirch, France) at $42^{\circ} \mathrm{C}$ for $8 \mathrm{~h}$. Slides were 
subsequently washed twice in $2 \mathrm{X}$ saline sodium citrate (SSC) and 0.1X SSC at room temperature. The buffer remaining on the slide was removed by rapid centrifugation $(4000 \mathrm{~g}, 15 \mathrm{sec})$. The fluorescence intensity was scanned using an Agilent Micro Array Scanner G2505B (Agilent Technologies, Inc., Santa Clara, CA, USA).

\subsubsection{Image and data analysis}

Image and data analysis were performed as previously described [14]. The signal and background intensity values for each spot in both channels were obtained using ImaGene 6.0 software (Biodiscovery, Inc, Proteigene, Saint-Marcel, France). Data were filtered using the ImaGene "empty spot" option, which automatically flags low-expressed and missing spots to remove them from the analyses. After base- 2 logarithm transformation, data were corrected for systemic dye bias by Lowess normalization using GeneSight 4.1 software (BioDiscovery, Inc, Proteigene). Ratios were then filtered in accordance with their variability among the 4 comparisons, and genes with high variability were removed from the analysis. Statistical analyses were performed using the free R 2.1 software (http://www.r-project.org). The log ratio between NAR-supplemented and control samples was analyzed with Student's $t$ tests to detect differentially expressed genes in the two nutritional conditions, and probability values were adjusted using a Bonferroni correction for multiple testing at $1 \%$ to eliminate false positives. Genes selected by these criteria are referred to as "differentially expressed genes".

To validate data of microarray study, real-time quantitative PCR was performed on the same RNA for a subset of genes identified as differentially expressed (RAPGEF1, FABP4, DGAT2, LCAT). High-Capacity cDNA Reverse Transcription Kit (Applied Biosystems, Foster City, CA, USA) was used to reverse transcribe RNA to cDNA. The primers were identified using Primer Express software (Applied Biosystems, Foster City, CA, USA). The qRT-PCR was carried out on Applied Biosystems 7900HT Fast Real-Time PCR System (Applied Biosystems, Foster City, CA, USA) using the Power SYBR ${ }^{\circledR}$ Green PCR Master Mix kit (Applied Biosystems, Foster City, CA, USA). After initial denaturation of $10 \mathrm{~min}$ at $95^{\circ} \mathrm{C}$, a two-step cycling conditions were: 15 seconds denaturation at $95^{\circ} \mathrm{C}$ and annealing/extension at $60^{\circ} \mathrm{C}$ for 30 seconds, cycled 40 times. The expression levels were calculated using the $\Delta \Delta \mathrm{Ct}$ method.
Differentially expressed genes were classified according to their role(s) in Gene Ontology cellular processes using GOstat software (http://gostat.wehi. edu.au/). Furthermore, differentially expressed genes were placed into cellular pathways using KEGG (Kyoto Encyclopedia of Genes and Genomes) database (http://www.genome.jp/kegg/tool/ map_pathway2.html) and Pathway Miner analysis software (BioRag: Bio Resource for Array Genes; http://www.biorag.org), which combines the pathway analysis capabilities of three different tools (KEGG, GenMAPP and Biocarta) through a Fisher Exact test [31]. MetaCore pathway analysis was also used to determine the transcription factors affected by NAR supplementation. Finally, Gene Ontology (GO) analysis (http://www.geneontology.org) was also performed to describe the associated biological processes of the differentially expressed genes overall.

\subsection{Statistical analyses}

A one-way ANOVA coupled with a multiple comparison test was used to compare effects of diets on biochemical parameters. Values are expressed as means \pm SEM. $P<0.05$ was taken to imply statistical significance.

\section{Results}

\subsection{NAR induces changes in hepatic lipid levels of mice fed $\mathrm{HF}-\mathrm{HC}$ diet}

Compared to untreated mice fed HF-HC diet, NAR supplementation significantly increased both TC and TG liver contents expressed either per $g$ of tissue $(+43 \%$ and $+63 \%$ respectively, Table 1$)$ or per $m g$ of hepatic protein content (data not shown). Nevertheless, NAR supplementation did not cause discernable hepatocyte damage, as evaluated by measurements of

Table 1

Hepatic lipid contents after an 18 -week supplementation period with $0.02 \%$ naringin in wild-type mice fed a high fat-high cholesterol diet

\begin{tabular}{lrr}
\hline & Control & \multicolumn{1}{c}{ NAR } \\
\hline Liver triglycerides $(\mathrm{mg} / \mathrm{g})$ & $21.0 \pm 6.2$ & $34.3 \pm 2.2^{*}$ \\
Liver cholesterol $(\mathrm{mg} / \mathrm{g})$ & $2.3 \pm 0.5$ & $3.3 \pm 0.4^{*}$ \\
\hline
\end{tabular}

Values are means \pm SEM ( $n=15$ per group), ${ }^{*} P<0.03$ versus control. 
Table 2

Insulin sensitivity after an 18-week supplementation period with $0.02 \%$ naringin in wild-type mice fed a high fat-high cholesterol diet

\begin{tabular}{lcc}
\hline & Control & NAR \\
\hline Glycaemia $(\mathrm{mg} / \mathrm{dL})$ & $86 \pm 12$ & $105 \pm 24$ \\
Insulinemia $(\mathrm{ng} / \mathrm{mL})$ & $0.71 \pm 0.35$ & $0.18 \pm 0.04^{* * *}$ \\
HOMA index & $10.91 \pm 1.95$ & $4.34 \pm 0.46^{* * *}$ \\
\hline
\end{tabular}

plasma ALAT $(19 \pm 4$ vs $20 \pm 6 \mathrm{IU} / \mathrm{L}, P>0.05)$ and ASAT activities $(70 \pm 5$ vs $68 \pm 5 \mathrm{IU} / \mathrm{L}, P>0.05)$ and by histological examination (data not shown) of the liver.

\subsection{NAR improves insulin sensitivity in mice fed $\mathrm{HF}-\mathrm{HC}$ diet}

Mice fed HF-HC diet supplemented with $0.02 \%$ NAR presented normalized insulinemia, known to be elevated by the high fat diet, without modification in glycaemia (Table 2). Calculation of HOMA index showed a significant improvement in insulin-resistance (Table 2).

\subsection{NAR modulates expression of genes in liver of mice fed HF-HC diet}

In the transcriptomic analysis performed in the present study, 1,766 genes were differentially expressed, with an average-fold change of 1.52 , following NAR supplementation compared to controls (Student $t$-tests using a Bonferroni correction at $0.01 \%$ ). Among these differentially expressed genes, 1,036 genes were up-regulated and 730 were downregulated (supplementary Table 1). Real-time quantitative PCR was performed using same RNA samples on 4 genes identified as differentially expressed in the liver and, for the majority of genes studied; the expression values were concordant with data from microarray analysis (supplementary Figure 1).

To decipher biological processes affected by NAR supplementation, the list of differentially expressed genes was subjected to gene-annotation enrichment analysis using GOstat bioinformatics resources. The list of GO groups of biological processes, which are highly represented, is presented in the supplementary Table 2 . This analysis revealed that differentially expressed genes are implicated in developmental process, cell differentiation or anatomical structure.
Classification of the differentially expressed genes using KEGG tool showed that several genes related to lipid metabolism were altered by NAR supplementation (i.e. fatty acid metabolism, arachidonic and linoleic acid metabolism) (Fig. 1). Among the signalling pathways, it appeared that insulin and Mitogen-Activated Protein Kinase (MAPK) signalling contain highest number of genes which expression is affected by NAR. Finally, expression of genes involved in cytokine-cytokine receptor interaction was also modulated. Further analysis by using MetaCore, allowed us to identify $\mathrm{HNF} 4 \alpha(P=1.2 \mathrm{E}-300)$ as well as $\mathrm{NF}-\kappa \mathrm{B}\left(P=3.17 \mathrm{E}^{-186}\right)$ as potential transcription factors involved in the observed alterations of gene expression.

\section{Discussion}

In this study we hypothesized that a change in plasma lipid concentrations and a subsequent reduction in the development of atherosclerosis (observed in a previous work following a nutritional NAR supplementation in wild-type mice on a HF-HC diet) [1] may originate from the effects of NAR on hepatic lipid metabolism. However, we observed an enhanced hepatic lipid accumulation in NAR supplemented mice, although the integrity of livers in the NAR-fed mice was not compromised, as revealed by the histological examination and the lack of changes in the plasma ALAT and ASAT activities. Thus, we investigated functional changes associated with NAR supplementation and determined at the transcriptional level its molecular target candidates in diabetogenic mice (fed HF-HC sucrose-rich diet).

\subsection{NAR modulates expression of genes involved in lipid biosynthesis and $\beta$-oxidation}

We observed that NAR supplementation was associated with an increase in hepatic TC and TG levels. Transcriptomic analysis of the liver revealed an up-regulation of the expression of genes coding ATP-citrate lyase (ACLY $\times 1.53)$ which is involved in de novo lipogenesis as donor of acetylCoA for the acetyl-CoA carboxylase reaction [32]. We also found that NAR supplementation led to the up-regulation of mRNA encoding two isoforms of acyl-coenzyme A:diacylglycerol transferases $($ DGAT1 $\times 1.35$, DGAT2 $\times 1.75)$ which are involved 


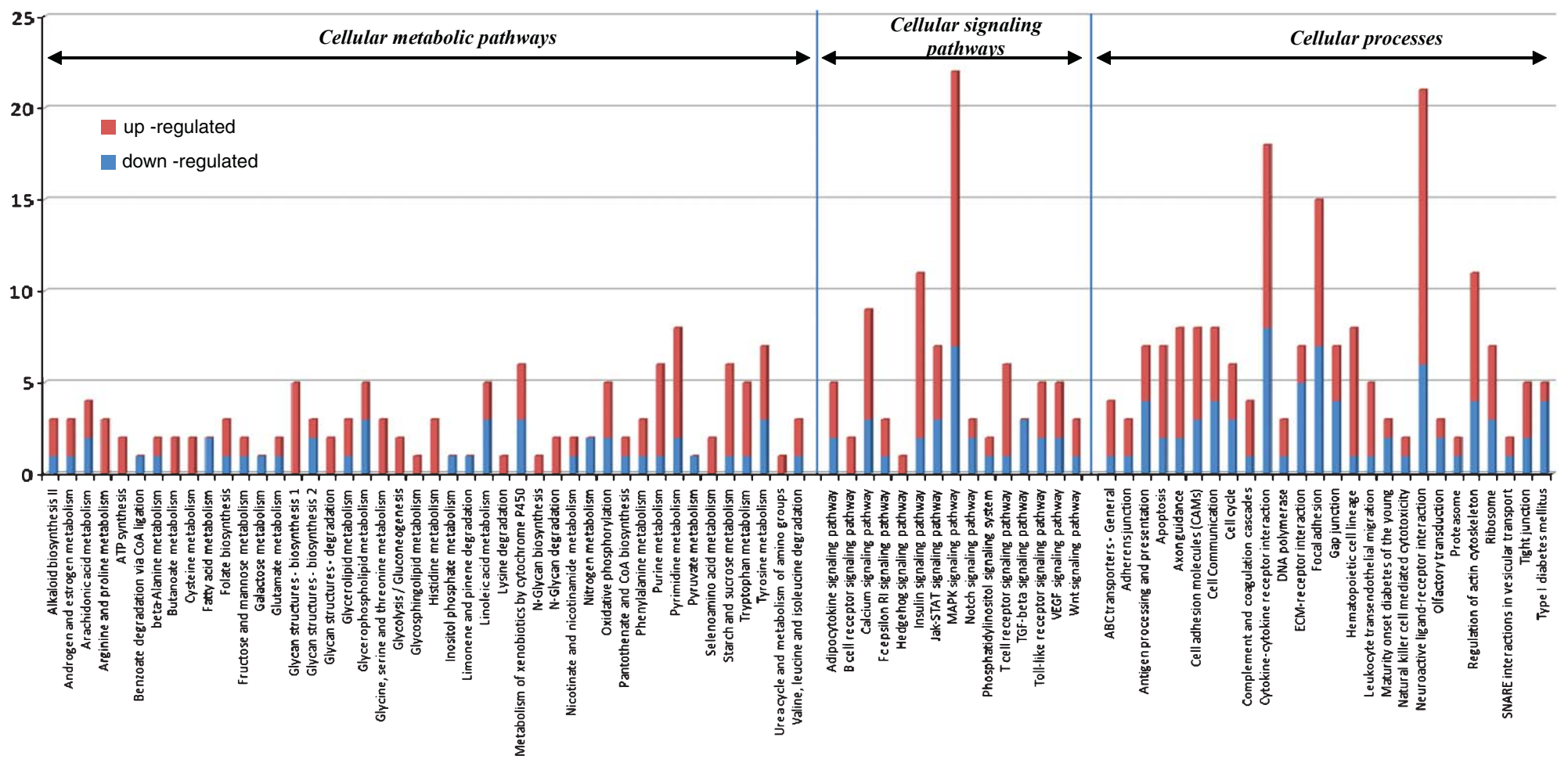

Fig. 1. Pathways affected by an 18 -week supplementation period with $0.02 \%$ naringin in the livers of mice fed a high fat-high cholesterol diet. Differentially expressed genes were analyzed across pathways using KEGG. 
in the final step of TG synthesis [33]. In addtion, the expression of the major lipid droplet-associated protein expressed in hepatocytes, adipose differentiationrelated protein (ADRP) or adipophilin (ADFP), increased after NAR feeding $($ ADFP $\times 1.85)$. At the surface of lipid droplets, the cellular organelles enclosing neutral lipid depots (triglycerides and cholesterol ester), ADFP protects lipid droplets from lipolysis. The direct consequence is a decrease in the release of lipids so decreasing their availability for lipoprotein synthesis. Consistent with this, mRNA levels encoding the lysosomal acid lipase A, an enzyme known to break down lipids such as cholesteryl esters and triglycerides, were reduced in the liver of NAR-supplemented mice $($ Lipa $\times 0.76)$. Furthermore, the mRNA levels of the peroxisomal $\beta$-oxidation key enzyme acyl-CoA oxydase (Acox $\times 0.77$ ), which is known to be induced by high-fat diet, were also down-regulated in the liver of NAR-fed mice. These results suggest a lower degradation rate for lipids in the liver of those animals, supporting the increased hepatic TG and cholesterol levels in the NAR-fed animals. Moreover, we showed a decrease in plasma VLDL levels in our model [1]. A lack of available neutral lipids in hepatocytes could be the main pathway for reduction in plasma VLDL levels. Indeed, this may lead to a degradation of apoB [34] and a subsequent decrease in VLDL assembly [35] as we did not observe any change in microsomal transfer protein expression in contrast to published in vitro data [36]. Interestingly, adfp-/- mice had a VLDL secretion rate significantly higher compared to adfp+/+ mice [37].

Overall, while major factors involved in lipid biosynthesis and storage were up-regulated, mRNA levels for proteins involved in pathways related to lipid utilization were down-regulated. These metabolic pathways are known to lead to the development of hepatic steatosis. Indeed, hepatic lipid accumulation is a hallmark of non-alcoholic fatty liver disease and is closely associated with insulin resistance in both rodents and humans [38], even in lean subjects with normal glucose tolerance [39]. In most cases, decreasing liver lipid accumulation was associated with improved insulin sensitivity. This is in agreement with Mulvihill et al. who used a pharmacological dose of naringenin, which is more bioavailable than NAR [24]. On the other hand, a recent study [40] showed increased insulin sensitivity and corrected insulin resistance in obese mice without affecting hepatic steatosis, indicating a clear dissociation between hepatic steatosis and insulin resistance, as was the case in our study. It has previously been reported that oil rich in polyphenols, such as olive oil, increased hepatic fat content [41] without impairment of insulin sensitivity. Moreover the retention of lipids in the liver is not necessarily damaging [42] as we demonstrated in livers from NAR-supplemented mice on HF-HC diet. Rather, the accumulation of lipids is perhaps indicative of a protective effect against extensive hepatic fibrosis and impaired hepatocellular function as suggested by Matsuzawa et al. [43]. Previously published works suggest an increase in oxidative stress as an important factor contributing to liver steatosis induced by a high-fat high-sucrose diet [44]. In our experiment, mice were fed for 18 weeks a high saturated fat $(15 \%$ Cocoa Butter) sucrose rich diet. The limited extent of the lipid peroxidation in our experimental conditions may be due to the use of saturated fat, along with an adequate vitamin E supply and the absence of alternations in hepatic enzymes. This does not totally exclude the occurrence of oxidative stress but suggests the preponderal role of direct action of SFA and sucrose on insulin resistance induction.

\subsection{NAR exerts insulin-like activity at molecular level}

An alternative explanation of the reduced VLDL fraction in plasma could be related to the effect of NAR on the insulin-signaling pathway. From in vivo [23] and in vitro studies [36, 45-47], naringenin has been shown to exhibit insulin-like activity. In vitro, naringenin reduced apoB secretion from HepG2 cells by activating both the phosphoinositol 3-kinase (PI3K) pathway and the MAP kinase pathway. One of the most relevant results from our transcriptomic study was the change found in the mRNA levels of proteins related to the insulin-signalling pathway. Indeed, in the present study, AKT1 substrate 1 (Akt1s1) gene expression was up-regulated 5.34-fold in mice fed the HF-HC diet supplemented with NAR when compared to HFHC control. This gene, also known as PRAS40, has been recently identified as a regulator and substrate of both $\mathrm{mTORC} 1$ and $\mathrm{PKB} / \mathrm{Akt}$, playing a major role as a novel physiological target of in vivo insulin action and a potential marker for insulin resistance [47]. Thus, phosphorylation of PRAS40 is increased by insulin in target tissues, and this response is reduced under conditions of high fat diet-induced insulin resistance. 
Furthermore, another highly differentially expressed genes after NAR supplementation was Rap guanine nucleotide exchange factor 1 (Rapgef $1 \times 1.98$ ), a gene encoding for a component of the CAP/TC10 pathway involved in insulin signalling [48]. Defects in the RAPGEF1 protein are thought to contribute to insulin resistance and type 2 diabetes [49].

We also observed that NAR significantly affected the expression of the MAPK signaling pathway, which mediates part of the effects of insulin. Overall, these results argue for an insulin-like effect of NAR in the liver of HF-HC-fed mice, which is supported by the improvement in the HOMA index that indicates an elevation of insulin sensitivity in response to NAR supplementation. While the full signalling pathway used by NAR to exert its insulin-like activity is not fully known, our data strongly suggest the involvement of the PRAS-PKB/Akt and mTORC1 systems as well as CAP/TC10 and also MAPK pathway in such functions. Such an insulin-like effect of NAR could in turn reduce apoB-containing lipoprotein secretion and explain the decrease in plasma VLDL observed in our previous work [1]. Moreover, bioinformatic analysis of nutrigenomic data, using Metacore software, allowed us to identify different transcription factors whos activity could be regulated by NAR and in consequence regulate expression of identified differentially expressed genes. Among these transcription factors, HNF $4 \alpha$ has been identified as a central transcription factor regulating hepatic genes expression following NAR supplementation $(P<0.05)$. Interestingly, $\mathrm{HNF} 4 \alpha$ regulates genes involved in glucose transport and metabolism and has been associated with diabetes onset, supporting an additional influence of NAR on carbohydrate metabolism [50].

Regarding potential molecular mechanisms of naringenin, it has been previously reported that this flavanone could induce the activity of both PPAR $\alpha$ and PPAR $\gamma$ through PGC1A activation [51, 52]. However, our bioinformatic analysis performed on the identified differentially expressed genes did not revealed PPARs as a potential transcription factors modulated by naringin in mice. The discrepancy between these two observations could be explained by the fact that the previous cited studies have been performed in vitro, using naringenin aglycone at concentrations as high as $200 \mu \mathrm{M}$. These experimental conditions do not take into account the low absorption of naringenin observed in vivo (with circulating levels in the microM range), nor the high conjugation activity, occurring both in the intestine and liver, that generates conjugated metabolites of naringenin which constitute the major forms of naringenin in plasma $[53,54]$.

\subsection{Modulation of inflammatory gene expression by NAR}

Further analysis of microarray data revealed modulation of inflammatory gene expression by NAR. It has been reported that cholesterol intake by apoE Leiden mice switches the liver from a resilient state to an inflammatory, pro-atherosclerotic state and modulates expression of pro-inflammatory and pro-atherogenic genes [55]. In our study, bioinformatic analysis identified NF- $\kappa \mathrm{B}$ as a potential transcription factor which activity could be regulated by NAR and, in consequence, modulates expression of NF- $\kappa \mathrm{B}$ dependant genes. We observed an up-regulation of genes encoding sphingosine-1-phosphate receptor $(\mathrm{Edg} 8 \times 2.34)$ involved in the decrease in T-cell-mediated immune responses [56], serglycin $(\operatorname{Srgn} \times 2.20)$ known to be important for the retention of key inflammatory mediators inside storage granules and secretory vesicles [57], $\mathrm{Ca}^{2+} /$ calmodulin-dependent protein kinase $($ Camk1d $\times 1.95)$ which can inhibit neutrophil differentiation and maturation [58], A20 (or tumor necrosis factor alpha induced protein 3 , Tnip2 $\times 2.66)$ and protein phosphatase $1 \mathrm{~A}(\mathrm{Ppm} 1 \mathrm{a} \times 1.89)$ acting as a IKK $\beta$ phosphatase [56-60], both of which are known to turn off inflammation signaling by inhibition of $\mathrm{NF} \kappa \mathrm{B}$ signalling a key regulator of inflammation and immune response [61]. Overall, changes in expression of these genes suggest a potential anti-inflammatory action of NAR.

Further effects of NAR on inflammatory processes were found related to the enzyme platelet-activating factor acetylhydrolase, also known as lipoprotein associated phospholipase A2 (Lp-PLA $2 \times 0.76)$. This enzyme cleaves oxidized phosphatidylcholine molecules produced during the oxidation of LDL, generating the soluble proinflammatory and proapoptotic lipid mediators. It has previously been shown that Lp$\mathrm{PLA}_{2}$, down-regulated in our study, plays a role in the development of atherosclerotic necrotic cores [62]. Moreover, the liver was causatively related to lesion initiation in the aorta because pro-atherogenic genes (genes encoding candidate inflammatory components reportedly or putatively involved in early lesion formation) were found to be up-regulated by dietary lipids 
[55]. Consequently, the modulation of expression of genes in the liver of mice fed HF-HC diet supplemented by NAR could be related to the reduced plaque progression observed in a previous study [1].

In summary, in the present work we show that NAR is able to counteract, at least in part, the induction of insulin resistance caused by a HF-HC sucroserich diet. However, NAR did not prevent diet induced lipid accumulation in the liver. Rather, transcriptomicbased analysis of the liver of NAR supplemented mice on HF-HC sucrose-rich diet revealed changes in the expression of genes that are modulated by consumption of this flavanone at nutritionally relevant dose. Firstly, several aspects of lipid metabolism and lipoprotein assembly and secretion were affected by NAR leading to hepatic lipid accumulation. Compared to previously published results, obtained under normal diet fed mice or hepatocytes cultured in standard conditions, our observations were made under conditions of enhanced FAs and cholesterol influx to the liver. This is of particular interest because it indicates the specific response to NAR in response to a nutritionally relevant metabolic challenge. As such, it may be hypothesized that the insulin-like potential of NAR could, at least in part, explain its action on hepatic lipid metabolism at the molecular level. Secondly, our transcriptomic data indicate the potential for the antiinflammatory action of NAR. Thus, increased lipid retention in the liver with, the reduced plasma levels in non-HDL lipoproteins and the reduction in HF$\mathrm{HC}$ diet-induced inflammation may help explain the antiatherogenic effect of NAR, which has previously been reported in the same animals.

\section{Acknowledgments}

We wish to thank the following people for their technical assistance: Valerie Lamothe from ENITAB, Sébastien Lepreux from the University of Bordeaux as well as Catherine Besson, Dominique Bayle and Séverine Thien from INRA. We also thank UNIJUS, the French association of fruit juice producers, who followed and communicated about this research program.

\section{Supplementary material}

This is available on-line: DOI 10.3233/NUA-20120010 .

\section{Financial support}

This project has received funding from the French National Research Agency in the context of the National Program for Research on Food and Nutrition (ANR06-PNRA-013).

\section{References}

[1] Chanet A, Milenkovic D, Deval C, Potier M, Constans J, Mazur A. Bennetau-Pelissero C, Morand C, Bérard AM, Naringin, the major grapefruit flavonoid, specifically affects atherosclerosis development in diet-induced hypercholesterolemia in mice. J Nutr Biochem. 2011; in press.

[2] Joshipura KJ, Hu FB, Manson JE, Stampfer MJ, Rimm EB, Speizer FE, Colditz G, Ascherio A, Rosner B, Spiegelman D, Willett WC. The effect of fruit and vegetable intake on risk for coronary heart disease. Ann Intern Med. 2001;134:1106-14.

[3] Bazzano LA, He J, Ogden LG, Loria CM, Vupputuri S, Myers $\mathrm{L}$, Whelton PK. Fruit and vegetable intake and risk of cardiovascular disease in US adults: The first national health and nutrition examination survey epidemiologic follow-up study. Am J Clin Nutr. 2002;76:93-9.

[4] Vivekananthan DP, Penn MS, Sapp SK, Hsu A, Topol EJ. Use of antioxidant vitamins for the prevention of cardiovascular disease: Meta-analysis of randomised trials. Lancet. 2003;361:2017-23.

[5] Bjelakovic G, Nikolova D, Gluud LL, Simonetti RG, Gluud C. Mortality in randomized trials of antioxidant supplements for primary and secondary prevention: Systematic review and meta-analysis. Jama. 2007;297:842-57.

[6] Bleys J, Miller ER 3rd, Pastor-Barriuso R, Appel LJ, Guallar E. Vitamin-mineral supplementation and the progression of atherosclerosis: A meta-analysis of randomized controlled trials. Am J Clin Nutr. 2006;84(4):880-7.

[7] Bin Q, Hu X, Cao Y, Gao F. The role of vitamin E (tocopherol) supplementation in the prevention of stroke. A meta-analysis of 13 randomised controlled trials. Thromb Haemost. 2011;105(4):579-85.

[8] Peters U, Poole C, Arab L. Does tea affect cardiovascular disease? A meta-analysis. Am J Epidemiol. 2001;154:495-503.

[9] Di Castelnuovo A, Rotondo S, Iacoviello L, Donati MB, De Gaetano G. Meta-analysis of wine and beer consumption in relation to vascular risk. Circulation. 2002;105:2836-44.

[10] Mink PJ, Scrafford CG, Barraj LM, Harnack L, Hong CP, Nettleton JA, Jacobs DR Jr. Flavonoid intake and cardiovascular disease mortality: A prospective study in postmenopausal women. Am J Clin Nutr. 2007;85: 895-909.

[11] Buijsse B, Weikert C, Drogan D, Bergmann M, Boeing H. Chocolate consumption in relation to blood pressure and risk of cardiovascular disease in German adults. Eur Heart J. 2010;31:1616-23.

[12] Norata GD, Marchesi P, Passamonti S, Pirillo A, Violi F, Catapano AL. Anti-inflammatory and anti-atherogenic effects of cathechin, caffeic acid and trans-resveratrol in apolipoprotein E deficient mice. Atherosclerosis. 2007;191:265-71. 
[13] Auclair S, Milenkovic D, Besson C, Chauvet S, Gueux E, Morand C, Mazur A, Scalbert A. Catechin reduces atherosclerotic lesion development in apo E-deficient mice: A transcriptomic study. Atherosclerosis. 2009;204:e21-7.

[14] Hooper L, Kroon PA, Rimm EB, Cohn JS, Harvey I, Le Cornu KA, Ryder JJ, Hall WL, Cassidy A. Flavonoids, flavonoid-rich foods, and cardiovascular risk: A meta-analysis of randomized controlled trials. Am J Clin Nutr. 2008;88(1):38-50

[15] Hooper L, Kay C, Abdelhamid A, Kroon PA, Cohn JS, Rimm EB, Cassidy A. Effects of chocolate, cocoa, and flavan-3-ols on cardiovascular health: A systematic review and meta-analysis of randomized trials. Am J Clin Nutr. 2012;3:740-51.

[16] Hooper L, Kroon PA, Rimm EB, Cohn JS, Harvey I, Le Cornu KA, Ryder JJ, Hall WL, Cassidy A. Flavonoids, flavonoid-rich foods, and cardiovascular risk: A meta-analysis of randomized controlled trials. Am J Clin Nutr. 2008;1:38-50.

[17] Tomas-Barberan FA, Clifford MN. Flavanones, chalcones and dihydrochalcones - nature, occurrence and dietary burden. J Sci Food and Agric. 2000;80:1073-80.

[18] Cassidy A, Rimm EB, O’Reilly EJ, Logroscino G, Kay C, Chiuve SE, Rexrode KM. Dietary flavonoids and risk of stroke in women. Stroke. 2012;4:946-51.

[19] Manach C, Scalbert A, Morand C, Remesy C, Jimenez L. Polyphenols: Food sources and bioavailability. Am J Clin Nutr. 2004;79:727-47.

[20] Reshef N, Hayari Y, Goren C, Boaz M, Madar Z, Knobler H. Antihypertensive effect of sweetie fruit in patients with stage I hypertension. Am J Hypertens. 2005;18:1360-3.

[21] Morand C, Dubray C, Milenkovic D, Lioger D, Martin JF, Scalbert A, Mazur A. Hesperidin contributes to the vascular protective effects of orange juice: A randomized crossover study in healthy volunteers. Am J Clin Nutr. 2010.

[22] Choe SC, Kim HS, Jeong TS, Bok SH and Park YB. Naringin has an antiatherogenic effect with the inhibition of intercellular adhesion molecule-1 in hypercholesterolemic rabbits. J Cardiovasc Pharmacol 2001; 38: 947-55.

[23] Mulvihill EE, Allister EM, Sutherland BG, Telford DE, Sawyez CG, Edwards JY, Markle JM, Hegele RA, Huff MW. Naringenin prevents dyslipidemia, apolipoprotein B overproduction, and hyperinsulinemia in LDL receptor-null mice with diet-induced insulin resistance. Diabetes. 2009;58: 2198-210.

[24] Mulvihill EE, Assini JM, Sutherland BG, DiMattia AS, Khami M, Koppes JB, Sawyez CG, Whitman SC, Huff MW. Naringenin decreases progression of atherosclerosis by improving dyslipidemia in high-fat-fed low-density lipoprotein receptornull mice. Arterioscler Thromb Vasc Biol. 2010;30:742-8.

[25] Jung UJ, Lee MK, Park YB, Kang MA, Choi MS. Effect of citrus flavonoids on lipid metabolism and glucose-regulating enzyme mRNA levels in type- 2 diabetic mice. Int J Biochem Cell Biol. 2006;38:1134-45.

[26] Huong DT, Takahashi Y, Ide T. Activity and mRNA levels of enzymes involved in hepatic fatty acid oxidation in mice fed citrus flavonoids. Nutrition. 2006;22:546-52.

[27] Lee CH, Jeong TS, Choi YK, Hyun BH, Oh GT, Kim EH, Kim JR, Han JI, Bok SH. Anti-atherogenic effect of citrus flavonoids, naringin and naringenin, associated with hepatic ACAT and aortic VCAM-1 and MCP-1 in high cholesterol-fed rabbits. Biochem Biophys Res Commun. 2001;284:681-8.
[28] Paigen B, Morrow A, Holmes PA, Mitchell D, Williams RA. Quantitative assessment of atherosclerotic lesions in mice. Atherosclerosis. 1987;68:231-40.

[29] Li Y, Gilbert TR, Matsumoto AH, Shi W. Effect of aging on fatty streak formation in a diet-induced mouse model of atherosclerosis. J Vasc Res. 2008;45:205-10.

[30] Folch J, Lees M, Sloane Stanley GH. A simple method for the isolation and purification of total lipides from animal tissues. J Biol Chem. 1957;226:497-509.

[31] Pandey R, Guru RK, Mount DW. Pathway Miner: Extracting gene association networks from molecular pathways for predicting the biological significance of gene expression microarray data. Bioinformatics. 2004;20:2156-8.

[32] Strable MS, Ntambi JM. Genetic control of de novo lipogenesis: Role in diet-induced obesity. Crit Rev Biochem Mol Biol. 2010;45:199-214.

[33] Millar JS, Stone SJ, Tietge UJ, Tow B, Billheimer JT, Wong JS, Hamilton RL, Farese RV Jr, Rader DJ. Short-term overexpression of DGAT1 or DGAT2 increases hepatic triglyceride but not VLDL triglyceride or apoB production. J Lipid Res. 2006;47:2297-305.

[34] Ginsberg HN, Fisher EA. The ever-expanding role of degradation in the regulation of apolipoprotein B metabolism. J Lipid Res. 2009;50 (Suppl):S162-6.

[35] Fisher EA, Ginsberg HN. Complexity in the secretory pathway: The assembly and secretion of apolipoprotein B-containing lipoproteins. J Biol Chem. 2002;277(20):17377-80.

[36] Borradaile NM, de Dreu LE, Huff MW. Inhibition of net HepG2 cell apolipoprotein B secretion by the citrus flavonoid naringenin involves activation of phosphatidylinositol 3-kinase, independent of insulin receptor substrate-1 phosphorylation. Diabetes. 2003;52:2554-61.

[37] Chang BH, Li L, Saha P, Chan L. Absence of adipose differentiation related protein upregulates hepatic VLDL secretion, relieves hepatosteatosis, and improves whole body insulin resistance in leptin-deficient mice. J Lipid Res. 2010;51:213242.

[38] den Boer MA, Westerterp M, de Vries-van der Weij J, Wang Y, Hu L, Espirito Santo SM, Kooistra T, Reiss P, Romijn JA, Havekes LM, Rensen PC. Ritonavir protects against the development of atherosclerosis in APOE*3-Leiden mice. Atherosclerosis. 2010;210(2):381-7. Epub 2009 Dec 1.

[39] Marchesini G, Brizi M, Morselli-Labate AM, Bianchi G, Bugianesi E, McCullough AJ, Forlani G, Melchionda N. Association of nonalcoholic fatty liver disease with insulin resistance. Am J Med. 1999;107(5):450-5.

[40] Monsenego J, Mansouri A, Akkaoui M, Lenoir V, Esnous C, Fauveau V, Tavernier V, Girard J, Prip-Buus C. Enhancing liver mitochondrial fatty acid oxidation capacity in obese mice improves insulin sensitivity independently of hepatic steatosis. J Hepatol. 2011.

[41] Arbones-Mainar JM, Ross K, Rucklidge GJ, Reid M, Duncan G, Arthur JR, Horgan GW, Navarro MA, Carnicer R, Arnal C, Osada J, de Roos B. Extra virgin olive oils increase hepatic fat accumulation and hepatic antioxidant protein levels in APOE-/- mice. J Proteome Res. 2007;6(10):4041-54. Epub 2007 Sep 11.

[42] Monetti M, Levin MC, Watt MJ, Sajan MP, Marmor S, Hubbard BK, Stevens RD, Bain JR, Newgard CB, Farese RV Sr, 
Hevener AL, Farese RV Jr. Dissociation of hepatic steatosis and insulin resistance in mice overexpressing DGAT in the liver. Cell Metab. 2007;6(1):69-78.

[43] Matsuzawa N, Takamura T, Kurita S, Misu H, Ota T, Ando H, Yokoyama M, Honda M, Zen Y, Nakanuma Y, Miyamoto K, Kaneko S. Lipid-induced oxidative stress causes steatohepatitis in mice fed an atherogenic diet. Hepatology. 2007;46(5):1392403.

[44] Lomba A, Milagro FI, García-Díaz DF, Marti A, Campión J, Martínez JA. Obesity induced by a pair-fed high fat sucrose diet: Methylation and expression pattern of genes related to energy homeostasis. Lipids Health Dis. 2010;9:60.

[45] Allister EM, Borradaile NM, Edwards JY, Huff MW. Inhibition of microsomal triglyceride transfer protein expression and apolipoprotein B100 secretion by the citrus flavonoid naringenin and by insulin involves activation of the mitogenactivated protein kinase pathway in hepatocytes. Diabetes. 2005;54:1676-83.

[46] Allister EM, Mulvihill EE, Barrett PH, Edwards JY, Carter LP, Huff MW. Inhibition of apoB secretion from HepG2 cells by insulin is amplified by naringenin, independent of the insulin receptor. J Lipid Res. 2008;49:2218-29.

[47] Nascimento EBM, Ouwens DM. PRAS40: Target or modulator of mTORC1 signalling and insulin action? Arch Physiol Biochem. 2009;115:163-75.

[48] Gaulton KJ, Willer CJ, Li Y, Scott LJ, Conneely KN, Jackson AU, Duren WL, Chines PS, Narisu N, Bonnycastle LL, Luo JC, Tong M, Sprau AG, Pugh EW, Doheny KF, Valle TT, Abecasis GR, Tuomilehto J, Bergman RN, Collins FS, Boehnke M, Mohlkel KL. Comprehensive association study of type 2 diabetes and related quantitative traits With 222 candidate genes. Diabetes. 2008;57:3136-44.

[49] Hong KW, Jin HS, Lim JE, Ryu HJ, Go MJ, Lee JY, Woo JT, Park HK, Oh B. RAPGEF1 gene variants associated with type 2 diabetes in the Korean population. Diabetes Res Clin Pract. 2009;84:117-22.

[50] Stoffel M, Duncan SA. The maturity-onset diabetes of the young (MODY1) transcription factor HNF4alpha regulates expression of genes required for glucose transport and metabolism. Proc Natl Acad Sci U S A. 1997;94:13209-14.

[51] Goldwasser J, Cohen PY, Yang E, Balaguer P, Yarmush ML, Nahmias Y. Transcriptional regulation of human and rat hepatic lipid metabolism by the grapefruit flavonoid naringenin: Role of PPARalpha, PPARgamma and LXRalpha. PLoS One. 2010;5(8):e12399.
[52] Goldwasser J, Cohen PY, Lin W, Kitsberg D, Balaguer P, Polyak SJ, Chung RT, Yarmush ML, Nahmias Y. Naringenin inhibits the assembly and long-term production of infectious hepatitis $\mathrm{C}$ virus particles through a PPAR-mediated mechanism. J Hepatol. 2011;55(5):963-71. Epub 2011 Feb 24.

[53] Manach C, Morand C, Gil-Izquierdo A, Bouteloup-Demange C, Rémésy C. Bioavailability in humans of the flavanones hesperidin and narirutin after the ingestion of two doses of orange juice. Eur J Clin Nutr. 2003;2:235-42.

[54] Brett GM, Hollands W, Needs PW, Teucher B, Dainty JR, Davis BD, Brodbelt JS, Kroon PA. Absorption, metabolism and excretion of flavanones from single portions of orange fruit and juice and effects of anthropometric variables and contraceptive pill use on flavanone excretion. Br J Nutr. 2009;5:664-75.

[55] Kleemann R, Verschuren L, van Erk MJ, Nikolsky Y, Cnubben NH, Verheij ER, Smilde AK, Hendriks HF, Zadelaar S, Smith GJ, Kaznacheev V, Nikolskaya T, Melnikov A, Hurt-Camejo E, van der Greef J, van Ommen B, Kooistra T. Atherosclerosis and liver inflammation induced by increased dietary cholesterol intake: A combined transcriptomics and metabolomics analysis. Genome Biol. 2007;8(9):R200.

[56] Kaneko T, Murakami T, Kawana H, Takahashi M, Yasue T, Kobayashi E. Sphingosine-1-phosphate receptor agonists suppress concanavalin A-induced hepatic injury in mice. Biochem Biophy Res Commun. 2006;345:85-92.

[57] Kolset SO, Tveit H. Serglycin - Structure and biology. Cell Mol Life Sci. 2008;65:1073-85.

[58] Gaines P, Lamoureux J, Marisetty A, Chi J, Berliner N. A cascade of $\mathrm{Ca} 2+/$ calmodulin-dependent protein kinases regulates the differentiation and functional activation of murine neutrophils. Experimental Hematology. 2008;36:832-44.

[59] Sun W, Yu Y, Dotti G, Shen T, Tan X, Savoldo B, Pass AK, Chu M, Zhang D, Lu X, Fu S, Lin X, Yang J. PPM1A and PPM1B act as IKKbeta phosphatases to terminate TNFalpha-induced IKKbeta-NF-kappaB activation. Cell Signal. 2009;21:95-102.

[60] Shembade N, Ma A, Harhaj EW. Inhibition of NF-kappa B Signaling by A20 through disruption of ubiquitin enzyme complexes. Science. 2010;327:1135-9.

[61] Monaco C, Paleolog E. Nuclear factor kappaB: A potential therapeutic target in atherosclerosis and thrombosis. Cardiovasc Res. 2004;61:671-82.

[62] Wilensky RL, Macphee CH. Lipoprotein-associated phospholipase $\mathrm{A}(2)$ and atherosclerosis. Curr Opin Lipidol. 2009;20:415-20. 